\title{
Individual Differences in L2 Speech Performance: The Role of Working Memory Capacity and Pre-planning Tasks
}

Zohreh Rezaei

English Department, Najafabad Branch, Islamic Azad University, Najafabad, Iran

Email: zohrehrezaei19@yahoo.com

Omid Tabatabaei

English Department, Najafabad Branch, Islamic Azad University, Najafabad, Iran

Email: tabatabaeiomid@yahoo.com

Doi:10.5901/mjss.2015.v6n2s1p533

\section{Abstract}

It has been argued that individual differences in working memory capacity (WMC) yield different oral performances in terms of complexity, accuracy and fluency (CAF). The present study is thus an attempt to examine the effect of WMC on L2 speech performance and its interaction with pre-planning tasks. To this aim, a math span test based on Robert and Gibson (2002) and Salthouse and Babcock (1991), as well as two descriptive tasks were used to measure WMC of a group of 30 advanced learners of English, and their oral production respectively. ANOVA have been used to analyze the collected data. The results showed that (1) pre-task planning led to gains in fluency and accuracy but not complexity of L2 speech performance, (2) no significant interaction existed between WMC and L2 speech performance in under- planning and no-planning conditions. (3) When the group was split into low and high span regarding their WMC, no differences were found between two groups in under-planning and no-planning conditions. This suggests that WMC plays a diminishing role among advanced learners regarding their oral performance.

Keywords: Working Memory Capacity, Pre-Task Planning, Oral Speech Performance.

\section{Introduction}

In the process of second language (L2) acquisition, and specifically in the case of oral performance, many factors and variables have proved to be essential and necessary. Among these factors, planning generally and pre-task planning particularly, is assumed to play a crucial role in oral speech acquisition and development. Another factor is the role of WMC, as a source of individual differences that interacts with planning in L1 acquisition and development.

Skehan (1998), points out that speaking is a complex construct that is basically measured through the three measures of 'complexity', 'accuracy', and 'fluency'. Therefore, the progress in speaking ability can be determined in terms of development in each of these aspects. There have been some studies over such factors as planning and the effect that they have on L2 learners' language production focusing on CAF (Ellis, 2009; Housen \& Kuiken, 2009; Wigglesworth \& Storch, 2009).

Studies on task planning and its role in L2 learners' oral performance have pointed out that when learners are provided with the opportunity to plan their task, their performance will be improved. (Ellis, 2005). The effects of manipulating planning time on oral speech performance have been examined in various studies (Ellis, 1987; Foster \& Skehan, 1996; Skehan \&Foster, 1997; Wigglesworth, 1997; Mehnert, 1998; Ortega, 1999; Yuan \& Ellis, 2003, GuaráTavares, 2008, Ahmadian 2012b). Planning has been investigated from different perspectives in these studies and most of them, in general, have reported a positive effect on L2 speech performance regarding CAF.

In addition, another way to address L2 speech production is to investigate the impact of WMC on speech performance. Working memory is defined as a "brain system that provides temporary storage and manipulation of the information, necessary for such complex cognitive tasks as language comprehension, learning, and reasoning" (Baddeley, 1992, p. 556). Working memory also in Miyake and Shah's definition (1999) is "those mechanisms or processes that are involved in the control, regulation, and active maintenance of task-relevant information in the service of complex cognition" (p. 450).

Succinctly put, there has not been much research designed to probe the effect of planning and its interaction with 
working memory on L2 speech performance. Therefore, a more clear comprehension of the association among WMC, pre-task planning and L2 speech performance may also assist researchers to clarify the nature of L2 acquisition and development.

\section{Literature Review}

One of the main questions in SLA research is what vindicates students' differential success in language learning. According to Gardner (1985) the variables that make differences among language learners are sub-divided into affective, cognitive and personality-related individual differences. In the area of cognitive psychology, it is relatively well accepted that individual differences in first language use may indicate individual differences in WMC (Fortkamp \& Bergsleithner, 2007). During the performance of cognitive tasks, working memory as the human cognitive system has a role in processing and storage of information (Baddeley \& Hitch, 1974; Daneman \& Carpenter, 1980; Miyake \& Shah, 1999). This process of working memory combines storage with the processing and manipulation of information, thus in this view working memory plays a more essential role in cognitive activities such as comprehension, reasoning and learning than previously supposed. (Baddeley, 2003).

Daneman and Carpenter (1980) investigated how individual differences in WMC affect the performance of cognitive tasks. They claimed that individuals with a larger WMC were more able to accomplish the cognitive processing involved in reading comprehension.

Fortkamp (2000) tried to investigate individual differences in WMC and their relationship with CAF and lexically density of L2 speech performance. Results from her study indicated a significant correlation between individuals' WMC and CAF. However, against her assumption, there was no significant correlation between WMC and weighted lexical density.

Mota (2003) followed the work of Fortkamp and examined the relationship between WMC and accuracy, fluency and both lexical and structural complexity. The results showed that working memory correlated with learners' CAF. In contrast, there was no correlation between WMC and lexical density.

The relationship between WMC and L2 speech performance has been a controversial issue and researchers in this area, have showed mixed results. D'Ely (2004) studied the relationship between WMC and L2 performance in different areas, one of which was speech production. Surprisingly, despite using the same WMC measures used by Fortkamp (2000), D'Ely did not find significant correlations between WMC and fluency.

Mizera (2006) examined the relationship between working memory and L2 fluency. The results showed weak correlations between WMC, speed and monitoring, and there were no other correlations between WMC and accuracy, pausing and repetitions.

Guara-Tavares (2009) explored the relationship between working memory, pre-task planning time and L2 speech performance. The scores correlated with learners' fluency, complexity, and accuracy. The results showed correlation between working memory scores and learners' fluency and accuracy.

\subsection{Pre-task planning}

Pre-task planning is a kind of planning which explains how production is affected by planning prior to performance. Ellis (2005) proposes that pre-task planning is not similar to pre-task activities, such as brainstorming, in terms of access to the task materials. During pre-task planning, learners get the actual materials for the task, whereas during the pre-task activities, learners do not receive the materials that they are going to use to perform the task. Besides that, task- planning provides learners an opportunity to employ a controlled process during a task.

Recently, L2 researchers have tended to investigate whether the manipulation of planned conditions have a positive effect on learners' oral or written performance in terms of CAF (e.g., Ellis, 1987, 2009; Ellis \& Yuan, 2004; Mehrang \& Rahimpour, 2010; Ortega, 1999; Skehan \& Foster, 1997; Tavakoli \& Skehan, 2005; Wigglesworth \& Elder, 2010; Wigglesworth \& Storch, 2009). Ellis (1987) was the first who carried out a significant study on the effect of planning on oral performance. The result of his study showed a correlation between the accuracy of performance and the availability of planning time.

Yuan and Ellis (2003) investigated the role of pre-task planning and on-line planning on learners' oral performance. The result of the study showed that pre- task planning enhanced fluency and grammatical complexity and on-line planning enhanced accuracy and grammatical complexity.

Mehrang and Rahimpour (2010) led a study to investigate the impact of planning conditions on L2 speech production. Results indicated that planning time had no effect on the accuracy and fluency of the learners' performance, 
but enhanced speech complexity when participants performed the unstructured task. Meanwhile under the planned condition, task structure did not affect the accuracy and complexity but led to more fluent performance.

Accordingly, in this study, an attempt was made to find the answer to the following three questions:

1) Is there any significant difference between the performances of participants in both groups (high \& low WMC) in planned and unplanned conditions in terms of CAF in oral speech performance?

2) Is there any significant difference between the groups in terms of CAF in oral speech performance?

3) Is there any significant interaction between conditions (planned \& unplanned) and groups in terms of CAF in oral speech performance? If so, do higher spans outperform the lower spans in terms of CAF in planned conditions?

Based on the research questions and in order to answer them, the following research hypotheses were formulated:

$\mathrm{H} 1$ : there is a difference between the performance of participants in planned and unplanned conditions, and planning opportunity significantly increase CAF of $\mathrm{L} 2$ speech production.

$\mathrm{H} 2$ : there is difference between groups in terms of CAF in oral speech performance.

$\mathrm{H}$ 3: there is interaction between conditions and groups in oral speech performance, so high WMC group will outperform the other group under planning conditions in terms of CAF.

\section{Method}

The present study aims to probe the role of working memory in speech production and also the way working memory interacts with pre-planning as a task- based variable that affects L2 speech production. Since there existed some qualitative as well as quantitative aspects which were supposed to be affected by L2 speech production, the researcher used both qualitative and quantitative methods of data collection.

\subsection{Participants}

The Participants of this study were 30 advanced EFL learners, all majoring in English language teaching at the MA level in different universities in Esfahan, Iran. At the beginning of the study, 120 MA students were selected. They were male and female students whose age ranged from 23 to 28 voluntarily consented to cooperate. Then, an Oxford Placement Test (OPT, Allan, 2004) was administered to ensure homogeneity, and then 56 homogeneous learners were selected. Due to the fact that the core concern of this study is learners' oral proficiency, an interview including 10 questions of high frequency in everyday conversations was also run to make sure learners were at the same level of oral proficiency. At last, after the interview 30 learners were chosen to serve as the participants of the study.

\subsection{Instruments}

For the purpose of this study a number of prominent materials and instruments were used to collect data:

\subsubsection{OPT}

An OPT (Allan, 2004) was administered to guarantee the participants homogeneity in terms of their English proficiency level. This test was used in order to exclude those subjects whose English proficiency level differed significantly from others and to neutralize the subject selection effect.

The participants' responses were scored on a scale of 50 points. Participants' scores ranged between 25 and 45 and based on their performance on OPT (Allan, 2004) those participants who had the score upper 31 were chosen (M= $57.24 ; \mathrm{SD}=1.02)$.

\subsubsection{Interview}

To make sure that the participants were at the same level of proficiency in terms of oral performance, an interview was run. In so doing, a researcher-made interview was used. Two experienced raters judged the interview on a speaking proficiency scale. Rating scale (Farhady, Jafarpur, Birjandi, 2003) was used to obtain interviewees total score. Then the ratings on each of the 5-scaled averaged for raters were transformed into values in the weighing table. (Farhady et al, 2003). Pearson's Correlations, which were run between each of the two ratings in the proficiency trial, proved to be significant (0.92), showing consistency among the ratings provided by the two different raters and the researchers' 
scores. In an attempt to guarantee sample homogeneity in terms of oral proficiency, for the sake of choosing advanced learners participants whose scores were at 2 standard deviation above the mean $(M=2.86)$ were opted. Finally, 30 were chosen to serve as the participants in this study. The rationale behind this decision was to ensure the homogeneity in the sample.

\subsubsection{Working Memory Span Test}

The participants' WMC was assessed using a version of math span tests Salthouse and Babcock's, (1991) and Robert and Gibson's (2002). This test consisted of some simple arithmetic problems in the form of $(X+Y=$ ?) Or $(X-Y=$ ?) form. $X$ and $Y$ can be single digit numbers between 1 and 9 in a set ranged from two at the outset of the test, up to six at the end and none of the answers to the problems were negative. In contrast to Salthouse and Babcock (1991) that provided three possible answers and asked their subjects to check off one, the math span test in this study follows Roberts and Gibson's (2002), version of this task. The test was administered in power point format and each problem was on the screen for 5 seconds. The participants were asked to provide the answers orally.

\subsubsection{Speaking tasks:}

\subsubsection{The first speech generation task}

To collect the first speech sample, each participant came out of the class individually and went to a separate room with the researcher. Necessary instruction to do the tasks was given to the participants in Persian. They were told that they would be recorded while speaking in English then the pictures were given to them to describe, compare and finally tell their own opinion about them. The pictures were selected from The Advanced Masterclass CAE, Aspomall and Capel (2001).

After that, each participant was given 45 seconds to see the pictures and then do the task. Moreover, they were asked to describe, compare and express their opinion in 2 to 3 minutes. The same process was followed for the second task.

\subsubsection{The second speech generation task}

The procedure for the second speech generation task was as the same as the first one, but this time the participants were instructed to plan the second task for 10 minutes after looking at the picture for 45 seconds.

\subsubsection{PRAAT software}

PRAAT software (version 5.3.52) was used in order to transcribe speech samples and identify pauses more precisely.

PRAAT software was created by Boersma and Weenink (2012) of the Institute of Phonetic Sciences, University of Amsterdam, and it is speech analysis software. It is used in ESL courses for relatively basic functions, like making waveforms for students to compare their pronunciation against that of a native-speaker model. In current study, PRAAT software was used to transcribe the speech samples based on AS units, and all speech samples were segmented. Finally, pauses were identified precisely, using that software.

\subsection{Scoring procedure of speaking tasks}

All the speech samples were transcribed, coded and analyzed. The samples were transcribed and pauses were identified and measured again using the computer software PRAAT. Since this study had focused on the CAF of the learners' performance; operational measures were chosen from other studies previously done on CAF. (e.g., Tavakoli, Vahid Dastjerdi, Esteki, 2011).

Fluency: Total number of pauses - in order to calculate fluency, the number of pauses of one second or more was counted. According to Mehnert (1998), no distinction was made between unfilled pauses and pauses that comprised fillers such as hm, urn, and uh. This measure was used in Foster and Skehan (1996), Foster and Skehan (1999), Mehnert (1998).

Complexity: Proportion of dependent clauses per AS unit (Wigglesworth \& Elder 2010). AS-unit is defined as "... a single speaker's utterance consisting of an independent clause, or sub-clause unit, together with any subordinate 
clause(s) associated with it" (Foster, Tonkyn \& Wigglesworth, 2000, p. 365). AS-unit is a syntactic measure that additionally uses pause and intonation phenomena to cut oral data into independent AS-units.

Accuracy: Percentage of error-free clauses - This measure is generally used for accuracy, and it is sensitive enough to detect differences in students' speech (Foster \& Skehan, 1996). This measure was used in Foster and Skehan (1996), Foster and Skehan (1999), Yuan and Ellis (2003), Wigglesworth and Elder (2010).

\section{Results}

This study included the coding and analysis of two-minute descriptions from The Advanced Masterclass CAE. Participants were divided into two groups based on their scores in working memory test and then $t$-test was run to find out if there is a significant difference between high and low a group.

Table 1: Independent Samples Test (t-test for Equality of Means)

\begin{tabular}{|c|c|c|c|c|c|c|c|c|c|}
\hline & & \multicolumn{3}{|c|}{$\begin{array}{c}\text { Levene's Test for } \\
\text { Equality of Variances }\end{array}$} & \multicolumn{2}{|c|}{$\begin{array}{c}\text { t-test for Equality } \\
\text { of Means }\end{array}$} & \multirow[b]{2}{*}{$\begin{array}{c}\text { Mean } \\
\text { Difference }\end{array}$} & \multirow[b]{2}{*}{$\begin{array}{l}\text { Std. Error } \\
\text { Difference }\end{array}$} & \multirow[b]{2}{*}{$\begin{array}{c}\text { 95\% Confidence Interval of } \\
\text { the Difference } \\
\text { Lower }\end{array}$} \\
\hline & & $F$ & Sig. & $t$ & $d f$ & $\begin{array}{l}\text { Sig.(2- } \\
\text { tailed) }\end{array}$ & & & \\
\hline \multirow[t]{2}{*}{$\begin{array}{l}\text { working memory } \\
\text { capacity }\end{array}$} & $\begin{array}{c}\text { Equal } \\
\text { variances } \\
\text { assumed }\end{array}$ & 3.741 & .065 & -10.709 & 23 & .000 & -12.96154 & 1.21030 & -15.46523 \\
\hline & & & & -10.535 & 18.835 & .000 & -12.96154 & 1.23033 & - 15.53818 \\
\hline
\end{tabular}

As it is clear in table 1, t-test shows that there is a significant difference between high and low groups concerning WMC. $p=-10.709$

Table 2 shows descriptive statistics among participants under planned and unplanned conditions in terms of CAF.

Table 2: Comparison of the means of CAF of oral speech performance across the groups under planned and unplanned conditions

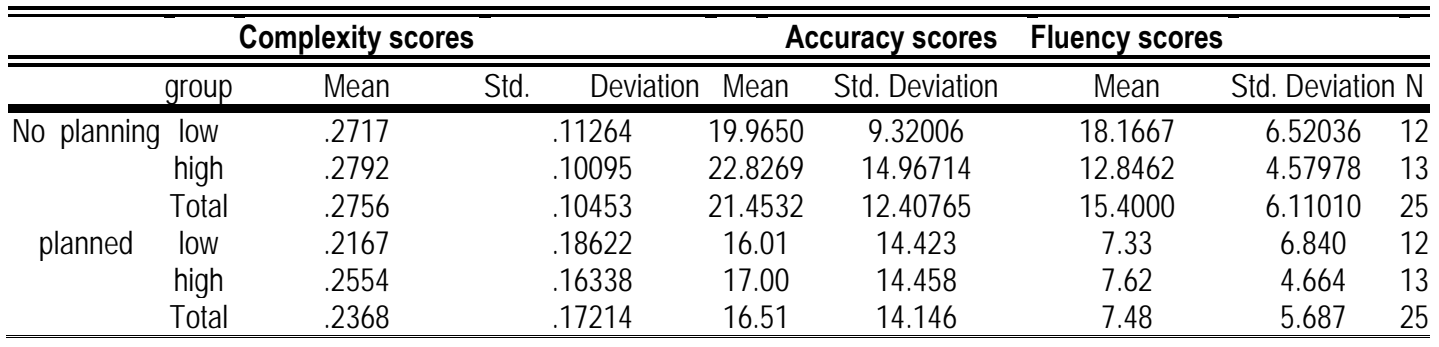

According to the table above, the mean of complexity and accuracy in high span group in unplanned condition is higher than that of the complexity and accuracy of the oral performance in the other group. However fluency in this group is not higher. Based on this table higher span group outperformed the CAF in planned condition but, the mean of participants in unplanned conditions is higher than the mean of participants in planned conditions in terms of CAF.

In order to find out whether the differences are statistically significant or not, general linear model, repeated measures ANOVA was employed to compare the means of CAF of the oral performance among individuals with different WMC concerning the role of pre-planning tasks. 


\subsection{Results Related to Complexity}

Table 3: ANOVA: The complexity of Speech, Tests of Within-Subjects Effects

\begin{tabular}{|c|c|c|c|c|c|c|}
\hline Source & \multicolumn{2}{|c|}{ Type III Sum of Squares } & \multirow{2}{*}{$\frac{d \mathrm{df}}{1}$} & \multirow{2}{*}{$\begin{array}{c}\text { Mean Square } \\
.019\end{array}$} & \multicolumn{2}{|c|}{ F $\quad$ Sig. Partial Eta Squared } \\
\hline \multirow{4}{*}{ condition } & Sphericity Assumed & .019 & & & 1.202 .284 & .050 \\
\hline & Greenhouse-Geisser & .019 & 1.000 & .019 & 1.202 .284 & .050 \\
\hline & Huynh-Feldt & .019 & 1.000 & .019 & 1.202 .284 & .050 \\
\hline & Lower-bound & .019 & 1.000 & .019 & 1.202 .284 & .050 \\
\hline \multirow{5}{*}{ condition * group } & Sphericity Assumed & .003 & 1 & .003 & .188 .669 & .008 \\
\hline & Greenhouse-Geisser & .003 & 1.000 & .003 & .669 & .008 \\
\hline & Huynh-Feldt & .003 & 1.000 & .003 & .669 & .008 \\
\hline & Lower-bound & .003 & 1.000 & .003 & .188 .669 & .008 \\
\hline & Sphericity Assumed & .371 & 23 & .016 & & \\
\hline \multirow{3}{*}{ Error(condition) } & Greenhouse-Geisser & .371 & 23.000 & .016 & & \\
\hline & Huynh-Feldt & .371 & 23.000 & .016 & & \\
\hline & Lower-bound & .371 & 23.000 & .016 & & \\
\hline
\end{tabular}

As shown in the above table, the results revealed that there is no statistically significant difference between participants' performance under both planned and unplanned conditions in terms of complexity $F(1,23)=1.2, p=.284>.05)$ and also there is no interaction between groups (low \& high WMC individuals) in planned \& unplanned conditions $F(1,23)=.188$, $p=.669>.05$ ). It means that individuals in one group do not outperform the other group in complexity of speech. Therefore the first and the second hypothesis regarding the complexity can be safely rejected.

Generally as shown in table 4 there is no difference between groups with low spans and high spans $F(1,23)=.25$, $p=.615>.05$. Thus we can conclude that WMC is not a significant factor in participants' performance. Thus the third hypothesis in terms of complexity can be rejected, too.

Table 4: Tests of Between-Subjects Effects

\begin{tabular}{ccccccc}
\hline \multicolumn{7}{c}{ Measure: COMPLEXITY } \\
\hline \hline Source & Type III Sum of Squares & df & Mean Square & F & Sig. & Partial Eta Squared \\
\hline Intercept & 3.265 & 1 & 3.265 & 126.748 & .000 & .846 \\
group & .007 & 1 & .007 & .259 & .615 & .011 \\
Error & .592 & 23 & .026 & & & \\
\hline \hline
\end{tabular}

\subsection{Results Related to Accuracy}

In terms of accuracy as demonstrated in Table 5, it concludes that there is a difference between participants' performance under planned and unplanned condition; but not in a significant level $F(1,23)=4.07, p=.055=.05$. Furthermore, there is no interaction between groups in planned and unplanned conditions in terms of accuracy $F(1,23)=$ $.153, p=.699>.05$. Thus, it can be concluded that per-planning task might have a positive effect on accuracy in speech production but there is no interaction between groups under planning and unplanned conditions. Therefore the first hypothesis can probably be accepted but the second hypothesis regarding accuracy can be rejected. It means that individuals in one group do not outperform the other group in accuracy of speech.

Table 5: ANOVA: The accuracy of Speech, Tests of Within-Subjects Effects

\begin{tabular}{|c|c|c|c|c|c|c|}
\hline & Source & Type III Sum of Squares & $\mathrm{df}$ & Mean Square & $\begin{array}{lll} & F & \text { Sig. }\end{array}$ & Eta Squared \\
\hline \multirow{3}{*}{ condition } & Sphericity Assumed & 299.978 & 1 & 299.978 & 4.070 .055 & .150 \\
\hline & Greenhouse-Geisser & 299.978 & 1.000 & 299.978 & 4.070 .055 & .150 \\
\hline & Huynh-Feldt & 299.978 & 1.000 & 299.978 & 4.070 .055 & .150 \\
\hline \multirow{2}{*}{\multicolumn{2}{|c|}{$\begin{array}{l}\text { Lower-bound } \\
\text { condition * groupSphericity Assumed }\end{array}$}} & 299.978 & 1.000 & 299.978 & 4.070 .055 & .150 \\
\hline & & 11.308 & 1 & 11.308 & . 153.699 & .007 \\
\hline
\end{tabular}




\begin{tabular}{llccccc} 
& Greenhouse-Geisser & 11.308 & 1.000 & 11.308 & .153 .699 & .007 \\
Huynh-Feldt & 11.308 & 1.000 & 11.308 & .153 .699 & .007 \\
& Lower-bound & 11.308 & 1.000 & 11.308 & .153 .699 & .007 \\
& Sphericity Assumed & 1695.402 & 23 & 73.713 & & \\
Greenhouse-Geisser & 1695.402 & 23.000 & 73.713 & & \\
Error(condition) & Huynh-Feldt & 1695.402 & 23.000 & 73.713 & & \\
& Lower-bound & 1695.402 & 23.000 & 73.713 & & \\
\hline \hline
\end{tabular}

As it is evident from Table 6 , there is no significant difference between low and high groups in terms of accuracy. $F$ (1, $23)=.15, p=.697>.05$ so the third hypothesis for accuracy can also be rejected.

Table 6: Tests of Between-Subjects Effect

Measure: ACCURACY

\begin{tabular}{ccccccc}
\hline \hline Source & Type III Sum of Squares & df & Mean Square & F & Sig. & Partial Eta Squared \\
\hline \hline Intercept & 17916.180 & 1 & 17916.180 & 61.093 & .000 & .726 \\
group & 45.530 & 1 & 45.530 & .155 & .697 & .007 \\
Error & 6744.952 & 23 & 293.259 & & & \\
\hline \hline
\end{tabular}

\subsection{Results Related to Fluency}

Table 7 shows the results of statistical analysis of ANOVA for fluency.

Table 7: ANOVA: The fluency of Speech, Tests of Within-Subjects Effects

\begin{tabular}{|c|c|c|c|c|c|c|}
\hline & Source & Type III Sum of Squares & $\mathrm{df}$ & Mean Square & Sig. & Eta Squared \\
\hline & Sphericity Assumed & 805.133 & 1 & 805.133 & 34.167 .000 & .598 \\
\hline condition & Greenhouse-Geisser & 805.133 & 1.000 & 805.133 & 34.167 .000 & .598 \\
\hline contantion & Huynh-Feldt & 805.133 & 1.000 & 805.133 & 34.167 .000 & .598 \\
\hline & Lower-bound & 805.133 & 1.000 & 805.133 & 34.167 .000 & .598 \\
\hline & Sphericity Assumed & 97.933 & 1 & 97.933 & 4.156 .053 & .153 \\
\hline condition * arou & Greenhouse-Geisser & 97.933 & 1.000 & 97.933 & 4.156 .053 & .153 \\
\hline conaltion ^ group & ${ }^{p}$ Huynh-Feldt & 97.933 & 1.000 & 97.933 & 4.156 .053 & .153 \\
\hline & Lower-bound & 97.933 & 1.000 & 97.933 & 4.156 .053 & .153 \\
\hline & Sphericity Assumed & 541.987 & 23 & 23.565 & & \\
\hline Frocos & Greenhouse-Geisser & 541.987 & 23.000 & 23.565 & & \\
\hline Error(contuntion) & Huynh-Feldt & 541.987 & 23.000 & 23.565 & & \\
\hline & Lower-bound & 541.987 & 23.000 & 23.565 & & \\
\hline
\end{tabular}

As it has been shown in this table, participants' scores in planning condition is statistically significant at 0.05 levels $F(1$, $23)=34.1, p=0.00<.05$. This relationship has been considered as positive. Thus, it can be concluded that per-planning task has a positive effect on fluency in speech production. Therefore the first hypothesis is retained regarding the fluency also there is interaction between two groups $F(1,23)=4.15, p=.053=.05$ but this interaction is significant at the probability level: $p=.053$

Table 8: Tests of Between-Subjects Effects

Measure: FLUENCY

\begin{tabular}{ccccccc}
\hline \hline Source & Type III Sum of Squares & df & Mean Square & $F$ & Sig. & Partial Eta Squared \\
\hline Intercept & 6590.885 & 1 & 6590.885 & 159.047 & .000 & .874 \\
group & 79.205 & 1 & 79.205 & 1.911 & .180 & .077 \\
Error & 953.115 & 23 & 41.440 & & & \\
\hline \hline
\end{tabular}


Table 8 shows that there is no significant difference between the groups in terms of fluency. $F(1,23)=1.91 p=.180$, $>.05$. It means that there is no difference in groups' performance regarding their WMC in fluency of speech. Therefore the third hypothesis can again be rejected concerning fluency.

\section{Discussion}

The purpose of this study was to find out if WMC is a matter of individual differences in L2 oral production and what the role of pre-task planning and its interaction with WMC in oral speech performance is.

Considering the results of data analysis regarding the first research question, it showed that there was a significant difference between the performance of participants in planning conditions in terms of accuracy and fluency but not complexity. It means that subjects produced more fluent and accurate language with pre-task planning. This finding is in line with the results of Ellis (1987) Foster and Skehan (1999), Skehan and Foster (1997).

As far as complexity is concerned, it seems possible that it connects to learners' willingness to take risks and use the "cutting edge" of their grammatical knowledge (Foster \& Skehan, 1996). Therefore, they need to pay more attention to the formal aspects of the language (to be more accurate and fluent). Moreover, the result of the study seemed to support the concept of trade-off effects between accuracy and complexity proposed by Skehan \& Foster (1997) in which learners try to prioritize some dimensions over others during the speaking tasks. Thus, it can be explained in terms of trade-off effects among features of speech production.

Considering the results regarding the second research question, the findings showed that there was no difference between individuals with high and low WMC. Regarding the complexity and accuracy of the oral output, the results are at odd with those of Fortkamp (2003) who found that higher span individuals are more capable of producing complex speech and are less tend to make mistakes as compared to lower spans. With regard to fluency, it is in line with that of Weissheimer \& Mota (2009) who, similarly, found no correlation between fluency scores of higher span subjects.

Due to the fact that this study examined the difference between low spans and high spans, among advanced learners, we can argue that because the learners were proficient in English language, there were no differences between them regarding WMC. According to Weissheimer \& Mota, (2009), proficient participants are more "proceduralized" and "automatized" regarding the processes involved in speech production, and they are able to speak more fluently and to develop more complex structures. Therefore, they are more able to employ efficient strategies for dealing with the test than WMC. Besides, in some previous studies such as (Daneman, 1991; Fortkamp, 1999, 2000, mota 2003), it was assumed that proficiency level would not affect the performance of the working memory test in English. Since learners were asked to produce sentences in the L2 in reading span test (RST) or speaking span test (SPT) to measure WMC, it can be concluded that their differences in proficiency affected their performance on the test. In fact, as these studies did not use an independent measure of proficiency, their working memory scores in the L2 were correlated with most measures of performance. Secondly, some researchers have used T- unit as the unit for analysis speech samples, but the measurement of sentence nodes per T-unit may not be a sensitive measure to measure speech performance. As Ellis \& Brakhuizen (2005) recommend using C- unit or AS- unit because they can take sub-clauses into account. Likewise, Foster et al, (2000, pp.362-363) argue that "AS-unit are more reliable than C-unit. This is because AS-unit can clearly distinguish among false start repetitions and self correction."

In addition, According to some studies of WMC, especially in the integration of controlled and automatic processes, working memory plays a greater role in earlier stages of acquisition (McLaughlin \& Heredia, 1996; Perlow, Jattuso, \& Moore, 1997; Woltz, 1988). Therefore, it seems possible that advanced learners, as they are proficient in the area of speaking do not show variation in scores related to their WMC.

Findings regarding the third second research question which are in a way at odds with Guará-Tavares (2011), and Ahmadian (2012b), showed no differences between high span individuals and low spans individuals under planning conditions. The question is that how can we account for this finding?

Although working memory in Level's model (1999) is responsible for maintaining essential information during cognitive tasks and we can deduce that those with higher WMC are more strategic during planning and can retrieve the planned information better than lower spans, it can be suggested that working memory plays a diminishing role in discriminating performance on second language speaking measures at higher levels of proficiency and both low and high spans similarly benefit the planning conditions. As Mizera (2006) claims, 'vocabulary depth', which is the result of development in language proficiency, may assist learners to retrieve lexical terms better and faster than WMC. Therefore, it is possible that the larger vocabulary span correlate more than that of WMC in speaking among advanced learners.

The results of the present study were in favor of planning tasks which should be taken into account when teaching and designing oral tasks. Based on the finding of this study, serving learners with the opportunity to plan their output 
assist them to acquire new, more difficult forms. It indicated that asking learners to perform tasks under certain conditions can persuade them to produce more accurate and fluent language.

The result of this study also revealed that there existed no difference between low span individuals and high spans under both planning and non-planning conditions in speech production, and both groups make benefits of planning time similarly. This result of the study, however, is not in harmony with the previous experiments as the majority of studies conducted in this regard mainly have reported that high spans outperform low spans in terms of CAF.

Another obtained result of this study that can be matched up with recent theories is the trade-off effects between accuracy and complexity measures of oral speech. Such trade-off effect means that one of these variables progresses at the expense of the other one. In fact, during the speaking tasks some dimensions over others are prioritized.

\section{References}

Ahmadian, M. J., (2012b). The relationship between working memory capacity and L2 oral performance under task-based careful online planning condition. Retieved July, 20, 2012 from http://www.academia.edu/1469114/

Allan, D. (2004). Oxford placement test. Oxford, England: Oxford University Press.

Aspomall, T. \& Capel, A., (2001). Advanced masterclass CAE. Oxford, Oxford University Press.

Baddeley, A. D. (1992). Working memory. Science, 255, 556-559.

Baddeley, A. D. (2003) Working memory and language: an overview. Journal of Communication Disorders 36.3: 189-208.

Baddeley, A.D. \& Hitch, G.J. (1974). Working memory. In G. Bower (ed.), The psychology of Learning and Motivation, vol. 8 (pp. 47-89). New York: Academic Press.

Boersma, P. \& Weenink, D. (2012): Praat: doing phonetics by computer [Computer program].Version 5.3.51, retrieved 2 June 2012 from http://www.praat.org/

D'Ely, R. (2004). A focus on learners' metacognitive processes: strategic planning, repetition and planning for repetition as catalysts of inter-language development. Unpublished research paper. UFSC.

Daneman, M. \& Carpenter, P.A. (1980). Individual differences in working memory and reading. Journal of Learning and Verbal Behavior 19, 450-466. Differences in second language learning. System, 31(3), 313-330.

Daneman, M. (1991). Working memory as a predictor of verbal fluency. Journal of Psycholinguistic Research, 20, 445-464. Retrieved October, 13,2012 from http://dx.doi.org/10.1016/j.jslw.2009.02.003

Ellis, R. \&. Barkhuizen, G. (2005). Analysing learner language. Oxford, Oxford University Press.

Ellis, R. (1987). Interlanguage variability in narrative discourse: style shifting in the use of the past tense. Studies in Second Language Acquisition, 9, 1-20.

Ellis, R. (2005). Planning and task performance in a second language. Amsterdam: Benjamins. Retrieved December, 4, 2012 from http://books.google.com/books

Ellis, R. (2009). The differential effects of three types of task planning on the fluency, complexity, and accuracy in 12 oral production. Applied Linguistics30.4:474509. http://dx.doi.org/10.1093/applin/amp042

Ellis, R., \& Yuan, F. (2004). The effects of planning on fluency, complexity, and accuracy in second language narrative writing. Studies in Second Language Acquisition, 26(1), 59-84. Retrieved, June, 14, 2012 from, http://dx.doi.org/10.1017/S02722631042634

Farhady, H., Jafarpur, A., \& Birjandi, P. (2006). Testing Oral Production. In the editiorial staff of SAMT (Ed.), Testing Language Skills From Theory to Practice (PP. 239-240) Tehran: The Center for Studying and Compiling University Books in Humanities (SAMT).

Fortkamp, M. B. M. (1999) Working memory capacity and aspects of L2 speech production. Communication and Cognition 32.3/4: 25996.

Fortkamp, M. B. M. (2000). Working memory capacity and L2 speech production: an exploratory study. Tese de doutorado. Florianópolis: Pós-Graduação em Inglês e Literatura Correspondente, UFSC.

Fortkamp, M. B. M. (2003). Working memory capacity and fluency, accuracy,complexity, and lexical density in L2 speech production. Fragmentos, 24, 69-104.

Fortkamp, M. B. M., \& Bergsleithner, J.M. (2007). Relationships among individual differences in working memory capacity, noticing, and L2 speech production. Revista Signo, vol 32, pp. 40-53.

Foster, P., \& Skehan, P. (1996). The influence of planning and task type on second language performance. Studies in Second Language Acquisition, 18, 229-323.

Foster, P., \& Skehan, P. (1999). The influence of source of planning and focus of planning on task-based performance. Language Teaching Research, 3(3), 215-247.

Foster, P., Tonkyn, A., \& Wigglesworth, G. (2000). Measuring spoken language: A unit for all reasons. Applied Linguistics 21, $354-375$.

Gardner, R. C. (1985). Social psychology and second language learning: The role of attitudes and motivation. London: Edward Arnold.

Guará-Tavares, M. G. (2008) Pre-task planning, working memory capacity and L2 speech performance. PhD thesis. Universidade Federal de Santa Catarina, Brazil.

Guará-Tavares, M. G. (2011). Pre-task planning, working memory capacity, and L2 speech, Organon, Porto Alegre, no 51, julhodezembro, p. 245-266

Housen, A., \& Kuiken, F. (2009). Complexity, Accuracy, and Fluency in Second Language Acquisition. Applied Linguistics, 30(4), 461473. . Retrieved 25, December, 2011 from http://dx.doi.org/10.1093/applin/amp042 
Levelt, W. J. M. (1989). Speaking: From intention to articulation. Cambridge, MA; MIT Press.

McLaughlin, B. \& Heredia, (1996).Information-processing approaches to research on second language acquisition and use. In William C. Ritchie, and Tej K Bhatia (eds.). Handbook of second language acquisition, Chapter 7, pp. 213-225. San Diego, CA: Academic Press.

Mehnert, U. (1998). The effects of different length of time for planning on second language performance. Studies in Second Language Acquisition, 20(1), 83-108.

Mehrang, F. \& Rahimpour, M. (2010). Investing effects of task structure on EFL learner s oral performance, English Language Teaching, Vol. 3, No. 4; December 2010 Retrived from www.ccsenet.org/elt

Miyake, A., \& Shah, P. (1999). Models of working memory: An introduction. In: A. Miyake \& P. Shah (Eds.), Models of Working Memory: Mechanisms of Active Maintenance and Executive Control (pp.1-27). Cambridge, U.K.: Cambridge University Press.

Mizera, G. J. (2006). Working memory and L2 oral fluency. PhD Dissertation. University of Pittsburgh.

Mota, M. B. (2003). Working memory capacity and fluency, accuracy, complexity and lexical density in L2 speech production. Fragmentos, 24, 69-104.

Ortega, L. (1999). Planning and focus on form in L2 oral performance. Studies in Second Language Acquisition, 21, $108-148$. http://dx.doi.org/10.1017/S027226319900107

Perlow, R. Jattuso, M. \& Moore, D. (1997). Role of verbal working memory in complex skill acquisition. Human Performance, 10, 283302.

Roberts, R., \& Gibson E. (2002). Individual differences in sentence memory. Journal of Psycholinguistic Research, 31, $573-598$. http://dx.doi.org/10.1023/A:1021213004302

Salthouse, T. A., \& Babcock, R. L. (1991). Decomposing adult age differences in working memory. Developmental Psychology, 27, 763776. http://dx.doi.org/10.1037/00121649.27.5.73

Skehan, P. (1998). A Cognitive Approach to Language Learning. Oxford: Oxford University Press.

Skehan, P., \& Foster, P. (1997). Task type and task processing conditions as influences on foreign language performance. Language TeachingResearch,1,185211 http://dx.doi.org/10.1177/136216889700100302

Tavakoli, M, Vahid Dastjerdi, H, Esteki, M, (2011). The Effect of Explicit Strategy Instruction on L2 Oral Production of Iranian Intermediate EFL Learners: Focusing on Accuracy, Fluency and Complexity, Journal of Language Teaching and Research, Vol. 2, No. 5, pp. 989-997, doi:10.4304/jttr.2.5.989-997

Tavakoli, p, \& Skehan, P. (2005). Strategic planning, task structure, and performance testing. In R. Ellis (Ed.), Planning and task performance in a second language (pp. 239 - 277). Amsterdam: Benjamins. UFSC.use on L2 working memory capacity and fluency. Unpublished research paper UFSC.

Weissheimer, J. \& Mota, M. (2009). Individual differences in working memory capacity and the development of L2 speech production, in Issues in Applied Linguistics 17, pp. 93-112.

Wigglesworth, G. (1997). An investigation of planning time and proficiency level on oral test discourse. Language Testing, 14, 85-106.

Wigglesworth, G., \& Elder, C. (2010). An investigation of the effectiveness and validity of planning time in speaking test tasks. Language Assessment Quarterly, 7(1), 1-24.York: Oxford University Press.

Wigglesworth, G., \& Storch, N. (2009). Pair versus individual writing: Effects on fluency, complexity and accuracy. Language Testing, 26(3),445-466. http://dx.doi.org/10.1177/026553220910460

Woltz, Dan J. (1988). An investigation of the role of working memory in procedural skill acquisition. Journal of Experimental Psychology, 117, No. 3, 319-331. http://www.4shared.com/get/xioJ44_i/Analysig_Learner_Language--El.html 